\title{
B2C E-Commerce Trust in Redress Mechanism (Cross Border Issues)
}

\author{
Chin Eang Ong \\ Monash University, Bandar Sunway, Petaling Jaya, Malaysia \\ ong.chin.eang@infotech.monash.edu.my
}

\begin{abstract}
The rise of consumer concerns of trust issue in e-commerce is due to the fact that when disputes occur in the cross-border environment, what is the level of protections (redress) that is available and which jurisdictions that is applicable and enforceable. This paper discuss the issue that with the current three major redress mechanisms, Online Dispute Resolution (ODR), Country of Origin and Country of Destination. Yet, consumers trust still an issue. It is well recognized that Cross Border environment and Jurisdictio $n$ that give rise to the concerns. This paper raises perhaps more important issues that relate to the gap and loophole that be living in the three redress mechanisms and jurisdictions.
\end{abstract}

Keywords: Redress, Online Dispute Resolution (ODR), Country of Origin, Country of Destination

\section{Introduction}

Technology and services from e-commerce already offer an enormous promising future to consumer with better information, new market choices and value of money in the electronic transactions. The potential of this electronic marketplace will not stop here but it will to develop and expand. However, ecommerce poses the same risks that happened in any marketplace, not everything has been positive for this online industry, where false advertising and frauds take places.

In this electronic marketplace, in choosing electronic transactions, consumer demands the same level of confidence and trust in the traditional marketplace. The reason is because there are several phenomena absent from e-commerce interaction compared with face-to-face interaction. The presumption of desired relational development is not present, the degree of intimacy possible in an e-commerce relationship is constrained, and the expansion of whatever e-relationship exists into other domain is limited.

Thus, consumer trust issues are not limited to privacy or security. Consumer trust also requires that consumers have access to fair and effective redress of problems arising in the online marketplace, at least an issue that is always claims by consumers "It is very easy to buy online, but it can made very difficult to return to e-tailers," can be resolved. Besides that, e-commerce, especially between consumers in one country buying goods or services from businesses based in other countries, will grow unabatedly only if consumers feel confident that their interests are sufficiently protected. Thus, online bus inesses of all stripes express a need to convince consumers that they are just as trustworthy as their off- line counterparts. But the question is how and where is the

Material published as part of these proceedings, either on-line or in print, is copyrighted by Informing Science. Permission to make digital or paper copy of part or all of these works for personal or classroom use is granted without fee provided that the copies are not made or distributed for profit or commercial advantage AND that copies 1) bear this notice in full and 2) give the full citation on the first page. It is permissible to abstract these works so long as credit is given. To copy in all other cases or to republish or to post on a server or to redistribute to lists requires specific permission from the publisher at Publisher@InformingScience.org starting point for an action?

\section{Significance of Trust and Redress}

Building trust that leads to satisfied customer is complicated but essential. All international trade is based on trust to some degree, but this is par- 


\section{B2C E-Commerce Trust in Redress Mechanism}

ticularly true for e-commerce. However, building consumer trust in e-commerce environment is not just the same as the trust that exist in bricks-mortar world. In e-commerce surroundings, businesses are building and sustaining the Virtual Trust. It is a promise (trust) that needs to restore affinity between businesses and consumers in this electronic environment with no close proximity of distance, difference in cultural, language, legislation and jurisdiction (Goldstein \& O'Connor, 2001)

In addition to that, as consumers settling down into the realities world where e-commerce has changed many aspects their daily lives, consumers are starting to question more and more: To what e xtend do I trust the other (business) to do what he or she promise to do? Besides, e-commerce, which can support the growth of cross-border consumer transaction at unprecedented levels, poses greater challenges to consumer trust as to what dependability consumers deserve when it concern with redress.

As way of illustration, consumers have been appealed to the Internet by million of reasons. One of the most attractive aspects of online shopping is access to million source goods and services without ever having leaving the home. But the front end of ordering and having something delivered to your doorstep is only half the story. The other half will be what happens if the wrong product arrives, unmerchantable quality, or an item is damaged. Would it be as easy as dropping the package in the mail for its return to sender?

Consumer trust can matter even more in the world of e-commerce, especially when transaction involves cross border and raise though question of legal jurisdiction in redress mechanisms. This means growth of e-commerce will not be achieved unless businesses realize consumers need to be able to rely on the clear redress mechanisms and consumer protection laws that are necessary for effective assurance will be available for them.

In traditional marketplace, consumers are aware of what their legal rights are and how to get access to a different method of enforcing their rights, such as through court of procedure. However, in the electronic marketplace or online transaction, delegating liability and providing access for redress might be a problem for consumers. Any transaction that is under a single jurisdiction, redress is always available within the court system. E-commerce is borderless; recourse to courts in disputes resulting from international electronic transactions is often complicated by difficult of which law applies, and which authorities have jurisdiction over such disputes.

Consumers are becoming enlightened with the convenience cross-border shopping. Furthermore, with the practical first acquaintance of the Euro as of January 2002 is foreseeable to further assist the progress of cross-border purchases (Brussels, 2001). When number of consumers starts doing online shopping from abroad, cross border increase, disputes will inevitably arise. Resolving disputes with bus inesses that appear to be hundred of kilometers away who speak a different language can be a major issue to consumers.

If consumers have, or think that no other means of redress available then it could be a major disincentives to cross-border shopping. Thus, uncertainty about redress and consumer protection problem in this cross border environment is impeding the potentiality of global electronic marketplace. How can the consumer be confident and trust that in the event of the service or goods being unsatisfactory - he or she will be able to complain and seek redress?

There are, of course, several choices or attempts when it comes to managing the cross border disputes in e-commerce transaction in fostering consumer confidence. Such as Online Disputes Resolution (ODR), Country of Origin and Country of Destination.

\section{ODR - Online Dispute Resolution}

Before the ODR, ADR (Alternative Dispute Resolution) is the old tradition dispute resolution that generally involves mediation (parties to a dispute reach a voluntary settlement through the assistance of a 
skilled facilitator) or arbitration (a legally binding ruling is made by a disinterested neutral arbitrator chosen by the parties to the dispute).

With the breakthrough of the technology, particularly online, ODR is one of the redress mechanisms that currently available to consumers. It is a wide range of mechanism and processes customized to help consumers in resolving cross border disputes. These ODR are not to replace the court judgment and any face-to-face dispute resolution methods or determination but act as a supplement with attention to cross border transactions.

ODR mechanisms might provide timely, low-cost, transparent and accessible response to consumers. It is believe that ODR is a dispute resolution that takes advantages of the Internet technology. ODR is likely to be growing fast in the future. Providing a rapid, efficient and effective in dispute resolution, heightened interest of traditional ADR institution in ODR and it is likely in settling disputes and as a mechanism for building trust.

What happened with ODR now it just the same as when e-commerce was introduced. E-commerce takes advantages of the Internet and this electronic marketplace was expanding. Consumers started to be pleased and attracted to the e-commerce by millions for reason of convenience and ease-of-use and it was the supplements of Brick and Mortar. After all, one of the attractive aspects of e-commerce is access to multiple sources of goods with borderless without having to leave home.

This is the point where the problem occurred; online environment, cross-border issue, no proximity of distance, and ambiguity of jurisdiction. It seems obvious to ask "would ODR raise up the same issue again, as what it occurred or confused consumer in e-commerce/online environment?"

If we look back it will bring to mind of everyone where and when the problem of consumer trust come s into existence - Online!

ODR poses particular challenges -

- If a specific model of ODR is designed which is aimed to be inexpensive for consumers, who will finance the proceeding?

- This situation raises a question whether business financed ODR mechanism is "impartial" or not.

- If ODR to be used in cross-border online disputes, whose law applies when disputants are in different jurisdiction?

- The disputes that occurred and needs of ODR are due to the cross border online transaction and with the deployment of ODR would that be a possibility of coming back to a same problem?

- Consumers might even faced vital difficulty in finding previously unidentified ADR provides in many regions of the world. According to International Chamber of Commerce, especially in Asian and Latin America. In most of the developing countries, notably country with low Internet penetration rates, the opportunity for ODR services is either still at early stage, or nonexistent. It is possible consumers at the region not even know what is right (International Chamber of Commerce, 2002).

This new breakthrough in the technology of dispute (ODR) in achieving the aim of creating trust and reliability is not just as simple as a mechanism that can provide a balancing of unequal bargaining power between businesses and consumers or provide an equally convenient and accessible to either party

Given these obstacles, the concern of ODR is not limited as to finding a simple answer to fill in the question of which law applies to cross border consumer truncations and which authorities have jurisdiction over disputes occurred over the transactions conducted over the Internet. Although, it is bound to 


\section{B2C E-Commerce Trust in Redress Mechanism}

undermine consumer trust and confidence in e-commerce but backbone connection "Enforceability" still a problem, particularly crucial for cross border disputes (Federal Trade Commission, 2001).

Therefore, a total or absolute international harmonization of applicable laws and international agreements among authority of this world on adequate and adapted jurisdiction nothing more than a theoretic solution, but it is a figment of an imagination that this is ever achievable. It is more like a "display nary solution with no applicability".

\section{Country of Origin and Country of Destination}

Although the legal approaches of country of origin and country of destination have been outlined but there is still no easy solution to the problem of jurisdiction and choice of law to consumer protection in electronic marketplace. Many EU co untries already are using a "country of destination" - or allowing transactions to be governed by the laws of the country of the buyer and "country of origin" to govern ecommerce transaction. At the end the que stion of what laws govern still arise as to (Goldstein, 2001):

- If online transaction should be governed by the rules in the country where transaction originated or completed or to be governed by the laws of the country of the buyer - who will be fully protected? Business or consumers? Or both parties will be shielded from any disputes or claims against business and consumer?

- Allowing the rules of the country of destination to govern is also not without complications. The course could conceivably make online merchants responsible for complying with hundreds of laws in hundreds of countries. This is because if courts are claiming jurisdiction over and applying their countries laws to websites of companies located outside their geographic boundaries. Such reach could subject companies to the courts and laws of virtually any country from which their website can be accessed (International Chamber of Commerce, 2001).

- The uncertainty of this legal paradigm also possible lead to the question of "has the business created a virtual storefront in the consumer's jurisdiction to make a sale, or has the consumer virtually traveled to the business's jurisdiction to make a purchase? Therefore, it is possible for a consumer orders a book from her home in Malaysia from a seller physically located in Me lbourne, it is as if the bookseller boarded a plane and delivered the book to the purchaser (consumer) in Malaysia, or as if the purchaser (consumer) flew to Melbourne to buy the book off-theshelf? (International Chamber of Commerce, 2001).

\section{Country of Origin}

The principle of country of origin and country of destination is to affirm that consumers must have an effective level on consumer protection and a significant access to any redress mechanisms in ecommerce. At the meantime, with this approach it applies physical border to ascertain rights in a borderless medium. This give the companies the difficulty to identify where is their consumers are located.

Hence, if this is the case, how could a business in which jurisdiction they may subject to regulatory and legal requirements? And the protection is for whom? (Computer and Internet Lawyer, 2000).

In the approach that is based on country of origin principle, businesses always take for granted as long as they adhere to their home country regulations; they will have the privilege to trade all over EU countries. As for the case governments can't impose any additional regulation on these e-tailers from other parts of EU countries. If an Australian business has complied with Australian regulations, it should be able to sell to Finland consumers without having to consider what the regulations in Finland are.

The achievement of the directive under this country of origin is not improving or sustaining consumer trust and confidence. This principle is not looking into consumer benefits, instead businesses are magnifying their own protection and passing out the indirect message to consumers as "under the country of 
origin, if any mistakes or errors occur, it will not my fault and you trade at you own risk" (Theresa Villiers, 2002)

\section{Country of Destination}

Other than business could be subjected to thousand of laws from which their website can be accessed. This principle will critically bound greater consumer choice and promising prices.

The complexity of this principle is further confused businesses when it is applied where consumers use "informediaries" or any online purchase of digital products and services where can be transmitted over the net, and pay with digital payment mechanisms that does not identify the purchaser. Businesses are concerns about not knowing the consumer online location or the geographic areas their sites reach. Under this circumstance, it is a great challenge to businesses as which law and forum to be applied.

In this situation, businesses, particularly SMEs (small medium enterprises), are further anxious about conformity of burdens in relation to this global marketplace. If this is to be the case, businesses are most likely to give up cross border online transactions completely, thus it will it will further limit the Internet's benefit to consumers.

\section{Jurisdiction and Cross-Border Issues}

Although the current redress mechanism - ODR, country of origin and country of destination are the major focus in this borderless electronic marketplace. But the answer in sustaining consumer trust in ecommerce remains a growing problem. One of the biggest obstacles in e-commerce is the thorny question of which countries jurisdiction go verns the cross-border issues. With business-to-consumer ecommerce "jurisdiction anywhere" is a real possible.

Any website can generally be access by anyone in any part of the world. This tends to make the "location" vague to businesses and consumers. The geography and location have been the fundamental on which laws to be applied. Any contracting transactions in e-commerce also correspond a challenge because Internet is a form of communication without static boundaries, thus, the vague of geography and locations have in fact contributed to the question of what laws to be followed in order for businesses and consumers understand their liabilities in this "jurisdiction everywhere" environment. In additional to that, Internet technology permit "pulls" - any particular consumer allows to surfs, read and downloads any information from a site, and "push" - any particular e-tailer sends information to consumer's PC automatically, which proliferate the complexity of question of legal contact in a state or other country (Pacini, Andrews \& Hillison, 2002)

Besides that, e-commerce still developing, courts do not follow the same thinking when conforming the online disputes and further confusing businesses and consumers due to different interpretations by different courts may result. Yet, businesses and consumers are in such a hurry to go online and at the meantime they fail to notice hidden serious legal consequences. Without doubt, consumers and businesses performed an electronic transaction without being knowing that they have constitutionally crossed beyond their home country border or become aware of that what occur to be a local action can develop into a global consequences (Podlas, 2000).

The volatile worldwide growth of e-commerce, its vulnerabilities, and lack of clear jurisdiction in ecommerce cross border issues have raised legitimate concerns with respect to adequacy of redress mechanism in online environment. Therefore the consequences lacks of trust from consumers are suffered by businesses due to the jurisdiction ambiguity in e-commerce. There is no easy compromise to these polar alternatives as to which laws should apply.

It is difficult or even impossible to comply with the laws of every potentially relevant jurisdiction. For example, if country of origin would to be applied, once a website is posted, it is instantly available 


\section{B2C E-Commerce Trust in Redress Mechanism}

worldwide to anyone with a computer. Thus, it is virtually impossible to prevent "advertising" in jurisdiction where such advertising is not permitted. And although in most cases states and countries have not imposed sanctions for advertising where it was not clearly targeted (by language, currency, local distributors) to their jurisdiction, a business that accepts orders and deals with consumers from that jurisdiction could nonetheless find itself subject to the whole range of applicable laws and regulations there.

And so, for example, it is arguable that if the EU endure passing the laws of country of destination and country of origin into cross border business to consumer e-commerce disputes. This will not regulate the issues but it will further restrain business to consumer e-commerce transactions, particularly SME (Small medium Enterprise) will out of business, just to avoid potential contradictory rules and regulations. What the global e-commerce need is an international coordinated law. However, any illcoordinated or incompatible regulations could pose the significant problem to the e-commerce, perhaps it will frame the global e-commerce into a puzzle - pieces.

Another possibilities the Jurisdiction remains vague in the Cross Border e-commerce environment are because there is lack of collaboration among nations and states. The Attitude Problem, which has, actually causes this. Peoples/countries realized there is a situation in this cross border environment but they are waiting for one party who is willing to move forward and do the rest of the work. Thus, regardless of which country is the most progressive or forward thinking for e-commerce, many countries still look to one country i.e. U.S or E.U to set the tone for this jurisdiction issue that affect the free world. At last, it ends with no uniform solution for this issue because when there is lack of collaboration there will be no compromise and no negotiating apparently equals no uniform soltion (Greenberg, 2001).

Although the cross border regulations (country of origin/destination) is still a legitimate legislation in EU. But these countries still have 15 separate markets in the EU, rather than one unified internal market.

Hence, building and sustaining consumer trust and confidence in this cross border electronic marketplace is not only a question of what redress mechanisms available to consumers. Acces sibility of redress mechanisms might not competent in assisting consumers gain trust if businesses still debating what amount to a fair and effective redress.

\section{Conclusion}

The answer to this problem is because there is no establish baseline of the jurisdiction in cross border issue. Thus, in sustaining consumer trust in this e-commerce environment, it doesn't matter which redress is to be applied. With the current available redress mechanisms and rules poses a limited circumstances.

A key concern now is therefore, should focus on the efforts in the provision of effective redress mechanism with an established and defined jurisdiction with a firm enforceability when cross border disputes arises. A difficult argument to make, perhaps, with no clear defined jurisdiction and enforceability how are such results enforced?

\section{References}

Brussels. (2001). New European Network To Help Consumers Settle Cross-Border Disputes Out-Of-Court. Available electronically fromhttp://europa.eu.int/comm/dgs/health consumer/library/press/press197 en.pdf Accessed September 23, 2003.

Computer and Internet Lawyer (2000). 'FTC issues report on consumer protection in global electronic marketplace' 17(11), 26.

Federal Trade Commission (2001). Public Roundtable On Dispute Resolution For Online Business To Consumer Contract. Available electronically from http://www.ftc.gov/os/2001/cbadrfrn.html Accessed September 13, 2002.

Goldstein, A. \& O'Connor, D. (2001). 'Navigating between Scylla and Charybdis '. Organization for Economic Cooperation and Development. The OECD Observer, 224, 72-75. 
Goldstein, N. (2001). Brussels I: A race to the top. Chicago Journal of International Law, 2(2), 521-524.

Greenberg, P.A. (2001). It's not a Small E-Commerce World, After All.E-Commerce Times, $23^{\text {rd }}$ Febuary.

International Chamber of Commerce (2001). Jurisdiction and applicable law in electronic commerce. Available electronically from http://www.iccwbo.org/home/statements rules/statements/2001/jurisdiction and applicable law.asp Accessed July 18, 2002.

International Chamber of Commerce (2002). Business-to-Consumer and Consumer-to-Consumer Alternative Dispute Resolution $(A D R)$ inventory Project. Available electronically fro $\mathrm{m}$ http://www.iccwbo.org/home/ADR/ADR\%20PROJECT\%20REPORT\%20final.pdf Accessed August 16, 2002.

Podlas, K. (2000). Global commerce or global liability? How e-commerce can lead to suit in foreign courts or under foreign law. The Mid-Atlantic Journal of Business, 36 (2/3), 89-101.

Pacini, A., Andrews, C., Hillison, W. (2002). Contracting in Cyberspace. The CPA Journal, 72(3), 65-67.

Theresa Villers MEP (2002). E-Commerce: A revolution or a legal nightmare? Available electronically from http://www.theresavilliers.com/link 13.htmAccessed September 16, 2002. 